\title{
RITO E REFORMA: BREVE COMPARAÇÃO ENTRE AS TRADIÇÕES BÍBLICAS E O PENSAMENTO CONFUCIANO
}

Pedro Regis Cabral ${ }^{1}$

\section{RESUMO}

Neste artigo comparamos brevemente o conceito de rito (禮) segundo a tradição chinesa confuciana e as tradições bíblicas (em especial a tradição profética do Velho Testamento e a tradição protestante). Demonstramos que, segundo os confucianos, o ritual deve estar ligado a uma atitude sincera e à moral para que mereça o nome de "rito"; por outro lado, a tradição protestante e o movimento profético tendem a ver o rito com desconfiança, como má religião em potencial, se não em essência. Apontamos que, nos textos antigos chineses, o rito está ligado à noção de ordem social, a qual deve refletir a ordem natural do cosmos. Por fim, especulamos como poderia ser formulada uma defesa confuciana do rito e como se daria sua crítica a uma atitude antirritualista. Para tanto, vamos nos valer dos clássicos chineses como O Livro dos Ritos $^{2}$, além de tradutores e comentadores contemporâneos.

PALAVRAS-CHAVE: Rito; Confucionismo; Reforma Protestante; O Livro dos Ritos.

\section{$\mathrm{O}$ rito e as tradições Bíblicas}

O “desencantamento" aparece, segundo Weber, primeiramente, na tradição profética de Israel.

Diz o Senhor através do profeta:

\begin{abstract}
Aborreço, desprezo as vossas festas, e não me deleito nas vossas assembleias solenes. Ainda que me ofereçais holocaustos, juntamente com as vossas ofertas de cereais, não me agradarei deles; nem atentarei para as ofertas pacíficas de vossos animais cevados. Afasta de mim o estrépito dos teus cânticos, porque não ouvirei as melodias das tuas liras. Corra, porém, a justiça como as águas, e a retidão como o ribeiro perene (BÍBLICA, s.d., online). ${ }^{3}$
\end{abstract}

Para Amós, Joel, Isaías, Jeremias et alli, o ritual, o sacrifício, a mágica do sacerdote são exemplos de má religião, espaço para a hipocrisia e são vazios. Os profetas, portanto, “desmagificaram” o mundo, sendo a mágica um método ritual de coerção do sagrado para certos fins. Os sacrifícios deveriam apaziguar Deus, e Ele faria chover e manteria as pragas longe dos campos. Haveria, antes do movimento profético, um sistema ético relativamente menos claro, no qual a norma social era expressa, em parte, por meio de

1 Doutorando em Filosofia e Estudos da Religião na Universidade de Macau.

E-mail: pedrorcabral@hotmail.com.

2 Traduzido para o português como "Cerimonial” pelo sinólogo Pe. Joaquim Angélico de Jesus Guerra. Usarei o caderno XIX, sobretudo.

3 BÍBLICA, Almeida Revisada Imprensa Bíblia. Amós 5: 21-24. BÍBLIA ONLINE, s.d. Disponível em: < https://www. bibliaonline.com.br/aa/am/5>. Acesso em: 09 nov. 2018. 
interdições e tabus. Até certo ponto, o código sacerdotal do Levítico se enquadra aqui, daí a tensão entre os sacerdotes e os profetas. Jesus continua esta tradição profética contra o ritual vazio e a má religião:

Ai de vós, escribas e fariseus, hipócritas! porque dais o dízimo da hortelã, do endro e do cominho, e tendes omitido o que há de mais importante na lei, a saber, a justiça, a misericórdia e a fé; estas coisas, porém, devíeis fazer, sem omitir aquelas. Guias cegos! que coais um mosquito, e engolis um camelo (BÍBLICA, s.d., online). ${ }^{4}$

"Serpentes!" "Raça de víboras! "Condenados!” Todo o cuidado ritual, o preciosismo da cerimônia convivendo com o escândalo da falta de compaixão. É bem conhecida a ira de Jesus contra os fariseus. Muitos episódios n'Os Evangelhos poderiam ilustrar este ponto.

Os protestantes recuperaram com mais entusiasmo que os católicos esta herança de crítica ao ritual vazio: Lutero, ao reafirmar a caducidade da Lei de Moisés e o calvinista iconoclasta combateram a figura do padre "mago", que faz o pecado desaparecer através do aparato ritual. Os sacramentos agora eram inúteis para a salvação. Em A Ética Protestante e o Espírito do Capitalismo:

O desencantamento do mundo: a eliminação da magia como meio de salvação, não foi realizado na piedade católica com as mesmas consequências que na religiosidade puritana (e, antes dela, somente na judaica). O católico tinha a sua disposição a graça sacramental de sua Igreja como meio de compensar a própria insuficiência: o padre era um mago que operava o milagre da transubstanciação e em cujas mãos estava depositado o poder das chaves. Podiase recorrer a ele em arrependimento e penitência, que ele ministrava expiação, esperança da graça, certeza do perdão e dessa forma ensejava a descarga daquela tensão enorme, na qual era destino inescapável e implacável do calvinista de viver (WEBER, 2004, p. 106).

Livres do suposto vazio da cerimônia, os protestantes iniciam a ascese intramundana. Se as ordens monásticas foram banidas, cada cristão deveria ser um "monge" e se dedicar inteiramente ao serviço e expansão do Reino de Deus. Só a Deus a glória. Talvez sob a influência da teologia paulina $^{5}$, o trabalho ganhou extraordinário peso. Para Lutero cada cristão teria sua "vocação" ou ofício da parte de Deus. Para certo tipo de calvinista, vivendo no que Weber chamou "era heroica" do capitalismo, o sucesso no trabalho e enriquecimento eram sinais de sua própria eleição divina.

Ainda sobre o antirritualismo protestante, Mary Douglas afirma que:

4 BÍBLICA, Almeida Revisada Imprensa. Mateus 23:23-24. BÍBLIA ONLINE, s.d., Disponível em: <https://www. bibliaonline.com.br/aa/mt/23>. Acesso em: 09 nov. 2018.

5 “...se alguém não quer trabalhar, também não coma.” Almeida Revisada Imprensa Bíblica Brasileira II, Tessalonicenses 3: 10. Disponível em: <https:/www.bibliaonline.com.br/aa/2ts/3>. Acesso em: 09/11/2018. 
A longa história do Protestantismo testemunha a necessidade de uma observação contínua da tendência da forma ritual a se consolidar e substituir os sentimentos religiosos. De onda em onda, a Reforma continuou a denunciar, violentamente, a incrustação do ritual. Desde que existe o Cristianismo, não será nunca hora de parar de repetir a parábola do Fariseu e do Publicano, de parar de dizer que as formas externas podem se tornar vazias e de ridicularizar as verdades de que se dizem portadoras. A cada novo século, tornamonos herdeiros de uma longa e vigorosa tradição anti-ritualista (DOUGLAS, 2012, p. 79).

Em Natural Symbols Douglas menciona certa "rejeição explícita dos rituais enquanto tais" e diz que "estamos testemunhando uma revolta contra o formalismo, até mesmo contra a forma" ${ }^{\circ}$ (DOUGLAS, 2007, p. 1).

Não sabemos até que ponto o público brasileiro estaria incluído no "nós" de Mary Douglas. Mas vivemos, de qualquer forma, no mesmo mundo secularizado e avesso às formas simbólicas como se tais necessariamente excluíssem qualquer sinceridade.

\section{Rito e confucionismo}

Do ponto de vista protestante o rito é inútil, uma “superstition”, como colocaria o puritano. O processo de "desmagificação", contudo, teria efeitos ainda mais amplos se considerarmos este fenômeno sob a ótica confuciana. O caractere que é geralmente traduzido do chinês às línguas ocidentais como "rito" (禮) tem um alcance semântico comparativamente maior do que os termos usados em sua tradução. Em nossa pesquisa encontramos as seguintes possíveis acepções, traduções e definições para a palavra-conceito "rito" (禮):

1. Atos de culto e rituais interpessoais de cortesia e diplomacia (SELIGMAN, WELLER,

PUETT, SIMON, 2008, p. 3);

2. “Cerimonial” (GUERRA, 1988);

3. “Civilização" (LEYS, 2005, p. 123, 124, 197, 201);

4. “Comportamento conforme a norma revelada pelo Céu" (HO, 2006, p. 176);

5. "Exteriorização dos sentimentos sinceros" (HO, 2006, p. 174);

6. "Misto de regras de etiqueta, de leis tradicionais seguidas pela aristocracia" (SINEDINO, 2012, p. XXIV)7;

7. “Ordem cósmica refletida na ordem social” (HU ; CHEN, 2012, p. 169.);

8. "Ritos são um meio para satisfação"" (XUNZI, 1963, p. 89).

Quanto às formas nas quais o "rito" se manifesta, Ho Yeh Chia explica:

Tradução nossa.

7 In: CONFÚCIO. Os Analectos. Tradução, comentários e notas Giorgio Sinedino. São Paulo: Editora Unesp, 2012.

8 故礼者养也。 
a maior e mais perfeita realização da virtude de socialidade e da justiça é a execução do rito. Esta execução pode ser realizada por diversas formas, por exemplo: pela literatura; pela música; pela pintura, ou seja, pela criação artística em geral; pelos sacrifícios ao Céu e aos pais ou aos ancestrais; pela forma adequada no cumprimento dos deveres, tais como no servir aos pais, no educar os filhos, no exercício da política pelos governantes etc; no convívio social; no trato das relações entre marido e mulher, entre irmãos, entre amigos; etc (HO, 2006, p. 178).

O ritual para católicos e a tradição sacerdotal israelita têm relação com perdão de pecados e salvação. Para os confucianos, o rito tem um raio de ação comparativamente mais amplo. Inclui, segundo o Livro dos Ritos, ordenamento social. Os confucianos seriam neste ponto muito modernos. Teriam, em adição à dimensão religiosa do rito, um entendimento descritivo ou científico dos seus efeitos na esfera da sociedade: o rito como instrumento para a política. N'Os analectos

Se conseguimos governar o país observando o ritual e demonstrando deferência, nada há mais para ser dito. Se não conseguimos governar o país observando o ritual e demonstrando deferência, qual a utilidade do ritual?? (CONFÚCIO, 2005, p. 18).

O rito deveria ensinar o indivíduo a se colocar diante da sociedade. Observamos que o conceito aparece relacionado à música n'Os Analectos ${ }^{10}$. A música e ritos organizam o interior do indivíduo e lhe ensinam seu lugar e seus deveres. Segundo o Livro da Piedade Filial, "música" e "ritos" podem, respectivamente, mudar os costumes e manter a ordem: "Para mudar os costumes e a tradição, não há nada como a música; para tranquilizar os líderes e ordenar o povo, não há nada como os ritos" ${ }^{11}$. No entanto, não serviria uma música qualquer. Por isso Confúcio faz distinção entre má música e "yăyue’" (雅乐), literalmente “música elegante”. Como cada instrumento na música ritual tem seu lugar e tempo próprios, cada indivíduo tem seu lugar definido na família e na sociedade. N'Os analectos, o mestre diz: "Quem não compreende os ritos é incapaz de ocupar o seu lugar"12 (CONFÚCIO, 2005, p. 114). Segundo o Livro dos Ritos, ou Cerimonial (conforme a tradução do sinólogo Pe. Joaquim Angélico de Jesus Guerra), as notas musicais correspondem à hierarquia e a certos aspectos da sociedade: "As cerimônias, a música, a legislação e os castigos têm o mesmo fim em vista: São maneiras de uniformizar os sentimentos do povo e fazer conhecer a sua maneira de governo" (GUERRA, 1988, p. 255). O rito (cerimônia) e a música como formas de governo ${ }^{13}$. Em seguida, ainda no caderno XIX (A) de Cerimonial, seção 4:

\subsection{3.}

10 Cf. Os Analetos de Confúcio: 3.3, 8.8, 11.1, 13.3, 16.2, 16.5 e 17.11.

11 移風易俗，莫善於樂。安上治民，莫善於禮， capítulo 12. Tradução para o inglês por Feng Xin-ming: “for changing the customs and traditions there is nothing better than music; for making the rulers at ease and the people orderly there is nothing better than etiquette". In: ZENG ZI. Xiao Jing - The Classic of Xiao. English translation and commentary by Feng Xin-ming (May 2007, revised February and May 2008). Disponível em: <http://www.tsoidug.org/>. Acesso em: 09 out. 2018. $12 \quad 20.3$.

13 禮樂刑政，其極一也；所以同民心而出治道也。 
A música e a administração pública andam ligadas uma com a outra: A nota Koq [宮] representa o Monarca; a nota Shyão [商] representa os funcionários; a nota Cawk [角] representa o povo; a nota Tyh [徵] representa o trabalho; a nota Yuh [羽] representa as coisas. Quando os cinco sons ou notas não andam desafinados, não há vozes destemperadas ou discordantes. Desafinada a nota Koq, é o excesso, é o príncipe altivo. Desafinada a nota Shyão, há um desvio, são os cargos públicos mal cumpridos. Desafinada a nota Cawk, o som é triste, é o povo descontente. A desafinação da nota Tyh, dá um som lamentoso, sinal de opressão no trabalho. Desafinada a nota Yuh é sinal de insegurança, por falta de abastecimentos. Quando todas as notas desafinam, prejudicam-se umas às outras. É o que se chama desenfreamento. Nesse caso, a ruína do Estado está por pouco (GUERRA, 1988, p. 255). ${ }^{14}$

Em seguida, na seção 11:

A música é para unir; as cerimônias para distinguir. A união produz o amor mútuo; a distinção leva ao respeito mútuo. Se a música se excede, haverá desvairamento; se é o cerimonial que se impõem, haverá desunião. A função das cerimônias e da música é uniformizar os sentimentos, e compor as maneiras e o exterior (GUERRA, 1988, p. 259). ${ }^{15}$

$\mathrm{Na}$ seção 14: "A verdadeira música revela a harmonia entre o céu e a terra. As cerimónias autênticas revelam os limites entre o céu e a terra"16 (GUERRA, 1988, p. 260).

Aqui a harmonia social se confunde com a harmonia musical.

Ainda o Livro dos Ritos: "O céu acima, a terra embaixo; todas as coisas no universo são diferentes entre si; o rito é estabelecido com base nestas diferenças" ${ }^{17}$ (HU; CHEN, 2012, p. 171). E em outro trecho: "O rito simboliza a ordem entre o céu e a terra"18 (HU; CHEN, 2012, p. 169).

As relações sociais, como já foi dito, devem refletir a ordem natural, cósmica, e os ritos são a encarnação simbólica desta ordem. No Yijing (易经), conhecido frequentemente pela grafia “I-Ching”:

Havendo o céu e a terra, há todas as coisas; havendo todas as coisas, há o homem e a mulher; havendo o homem e a mulher, há o esposo e a esposa; havendo esposa e esposo, há pais e filhos; havendo pais e filhos, há o monarca e súditos; havendo monarca e súditos, há em cima e embaixo; havendo em cima e embaixo, os ritos podem ser implementados (ZHOU, 2012, p. 378). ${ }^{19}$

Em O Cerimonial, seção 22, caderno XIX (A), tradução de Pe. Guerra:

O Céu (Deus) é nobre, e o mundo (terra) humilde. Por aí assentam o Soberano e os vassalos. A ordem entre baixos e altos, com os nobres e os humildes nos seus lugares; bem como o

14 聲音之道，與政通矣。宮為君，商為臣，角為民，徵為事，羽為物。五者不亂，則 無怗您之音矣。宮亂則荒，其君驕。商亂則陂，其官壞。角亂則憂，其民怨。徵亂則哀， 其事勤。羽亂則危，其財匱。五者皆亂，迭相陵，謂之慢。如此，則國之滅亡無日矣。 15 樂者為同，禮者為異。同則相親，異則相敬，樂勝則流，禮勝則離。合情飾貌者禮樂之事也。

16 樂者，天地之和也；禮者，天地之序也。

17 天高地下，萬物散殊，而禮制行矣。

18 禮者，天地之序也。

19 有天地然后有万物，有万物然后有男女，有男女然后有夫妇，有夫妇然后有父子，有父子然后有君臣，有 君臣然后有上下，有上下然后礼义有所错。 
movimento e o repoiso a seus tempos, aponta às diferenças entre o que é pequeno e o que é grande e importante. Daí o agrupamento por espécies, e a distinção das coisas pelos seus géneros. De facto a natureza e os destinos não são os mesmos. Os modelos que vem do céu, na terra se revelam. E assim, as cerimônias estão a dizer a diferença do céu e da terra. (GUERRA, 1988, p. 264). ${ }^{20}$

\title{
É, mais uma vez, harmonia e ordem social refletindo a harmonia e a ordem cósmicas. O rito aqui não tem
} relação com a expiação de pecados e salvação da alma. Há, contudo, clara dimensão religiosa como a própria constituição do ideograma “rito" (禮) aponta. O radical à esquerda (示) é, um altar; à direita, uma taça com ramos (曲) sobre um recipiente (豆), os quais são oferecidos à divindade (LI, 2008, p. 4; HO, 2006, p. 175).

O entendimento confuciano a respeito do rito, mais descritivo ou científico em relação às tradições bíblicas mencionadas, é levado a um novo nível em Xunzi (荀子, 312 — ? a.C.) ${ }^{21}$.

Por tanto, o Céu e a terra produzem o cavalheiro, e o cavalheiro traz ordem ao Céu e à terra. O cavalheiro forma uma tríade com o Céu e a terra; ele é o controlador de todas as coisas, o pai e a mãe do povo. Sem o cavalheiro, o Céu e a terra não terão ordem e princípios rituais não terão unidade ${ }^{22}$ (XUNZI, 1963, p. 44).

Seguindo a tradução de Watson e a leitura de Seligman, Weller, Puett e Simon, é o junzi, é “o cavalheiro", quem dá ao mundo padrões de ordem. Os ritos foram criados pelos reis santos da antiguidade chinesa com vista a certos fins ${ }^{23}$. São, portanto, um artifício humano, um ato de criação do cavalheiro, não necessariamente refletindo uma ordem já dada e observável, como ensina o Livro dos Ritos ${ }^{24}$. Há, observa-se aqui, um entendimento materialista, possivelmente agnóstico em relação aos ritos, aos fenômenos naturais e à religião:

\begin{abstract}
Você ora por chuva e chove. Por quê? Por nenhuma razão em particular, digo eu. É exatamente como se você não tivesse orado por chuva e chovesse de qualquer forma. O sol e a lua sofrem um eclipse e você tenta salvá-los; ocorre uma seca e você ora por chuva; você consulta as artes de divinação antes de tomar uma decisão sobre uma questão importante. Mas não se pode realmente obter nada por meio de tais cerimônias. Elas são feitas meramente como ornamentos. Portanto, o cavalheiro as considera como ornamentos, mas o povo comum as considera sobrenaturais. Feliz aquele que as considera ornamentos; infeliz aquele que as considera sobrenaturais ${ }^{25}$ (XUNZI, 1963, p. 85).
\end{abstract}

20 天尊地卑，君臣定矣。卑高已陳，貴賤位矣。動靜有常，小大殊矣。方以類聚，物以群分，則性命不同矣。 在天成象，在地成形；如此，則禮者天地之別也。

21 XUNZI. Hsün Tzu Basic Writings. Traduzido por Burton Watson. Nova Iorque e Londres: Columbia University Press, 1963, p. 1, 2. Data de nascimento aproximada.

22 故天地生君子，君子理天地；君子者，天地之参也，万物之总也，民之父母也。无君子则天地不理，礼义无 统。

23 先王惡其亂也，故制禮義以分之, “Os reis antigos odiaram tal desordem e portanto estabeleceram princípios rituais”. XUNZI. Hsün Tzu Basic Writings. Traduzido por Burton Watson. Nova Iorque e Londres: Columbia University Press, 1963, p. 89.

24 "Quem conhece bem o céu e a terra, esse é que pode promover as cerimônias e a música.". GUERRA, Joaquim Angélico de Jesus. O Cerimonial (Ley ky) 2, seção 18, caderno XIX A. Macau: Jesuítas Portugueses, 1988, p. 262. 25 Traduzimos do inglês de Watson. Texto original: “雩而雨，何也？日：無伦也，猶不雲而雨也。日月食而救之， 天旱而零，卜筮然後決大事，非以為得求也，以文之也。故君子以為文，而百姓以為神。以為文則吉，以為神則凶也" 
Zi Yue: revista de graduação de estudos sinológicos. São Paulo: Portal de Revistas da USP, v. 1, n. 1, 2020.

Vê-se que os ritos chegaram a ser racionalizados e esvaziados de seu conteúdo mais claramente religioso, místico já no século terceiro antes de Cristo. Todavia, esta não é a única posição confuciana possível e Xunzi é considerado um confuciano heterodoxo por oposição a Mêncio ${ }^{26}$. Jiang Qing, por exemplo, um expoente do "novo confucionismo", considera que a religiosidade do confucionismo, diferentemente do que defende Li Zehou ${ }^{27}$, não é a padronização, sistematização e racionalização de antigas cerimônias de feitiçaria. "É, pelo contrário, a crença na divindade contida nas práticas religiosas antigas que Confúcio preservou no processo de estudo dos clássicos, o 'Céu' pessoal das três primeiras dinastias que preservou e fez disto o fundamento do rito"28.

\section{Rito e Moral}

Outro aspecto do conceito de rito conforme os chineses o entendem é o seu caráter moral, o que soa paradoxal a ouvidos ocidentais. Cabral (2017) investigou como a sensibilidade cultural de brasileiros (22 alunos de mandarim) e chineses (29 estudantes universitários) pode afetar o ensino de mandarim como segunda língua. O questionário aplicado perguntava, entre outras questões, se concordariam ou não, e em que grau, com as afirmações seguintes (abaixo tabelas com os resultados comparados dos dois grupos; os números apresentados nos gráficos são o número absoluto de entrevistados e o percentual):

26 O pensamento de Mêncio a respeito do rito já foi bem trabalhado e exposto na tese de doutorado de Ho Yeh Chia. Não o comentaremos aqui.

27 “它的一个基本特征，是原始巫术礼仪基础上的晚期氏族统治体系的规范化和系统化”， ou： “Uma característica peculiar sua [do rito de Zhou] é a sistematização e padronização do fundamento ritual mágico original feitas posteriormente pela classe de governantes de clãs ”. LI, Zehou (李泽厚). 中国古代思想史论 (Sobre a História do Pensamento Antigo Chinês). Pequim: 生活·读书·新知三联书店 (Shenghuo dushu xinzhi sanlianshudian), 2008, p. 2. 28 “而是相反，孔子在经学系统中保存了巫术的神灵信仰，保存了三代人格神的 “天”，并以之作为“礼” 的基础。”JIANG, Qing (蒋庆). 追求人类社会的最高理想: 中和之魅一一蒋庆先生谈儒家的宗教性问题, Gui Yang, 2004. Disponível em: <http://www.confucius2000.com/confucius/zqlrshdzglxzhzmjqtzj.htm>. Acesso em: 28/06/2014, 
Gráfico 1: Às vezes precisamos mentir para sermos educados e gentis com os outros. ${ }^{29}$

\section{Brasileiros}

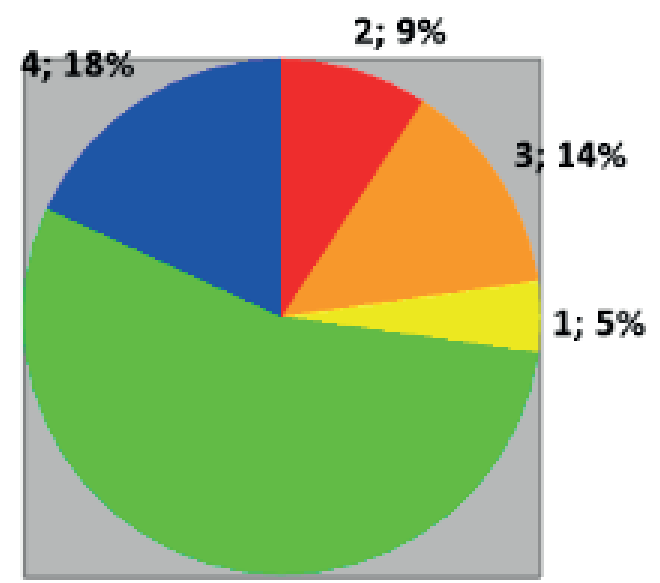

$12 ; 54 \%$
Chineses

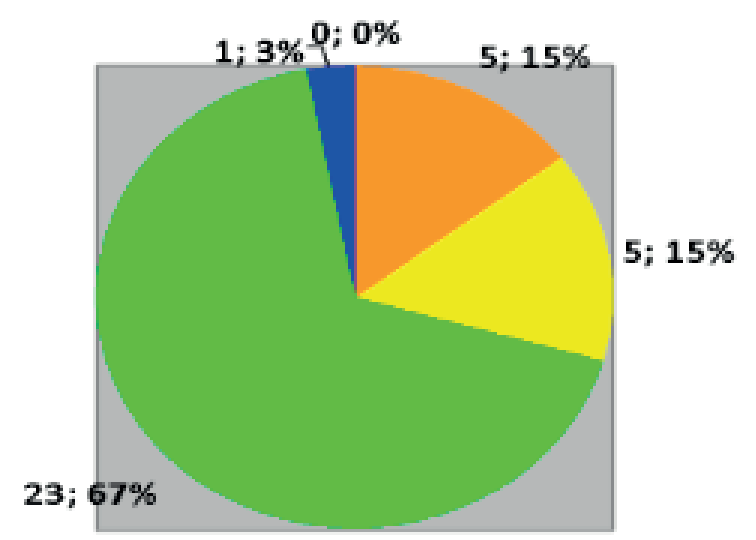

\begin{tabular}{|l}
$\square$ Discorda totalmente \\
Discorda \\
Não sabe \\
Concorda \\
$\square$ Concorda totalmente
\end{tabular}

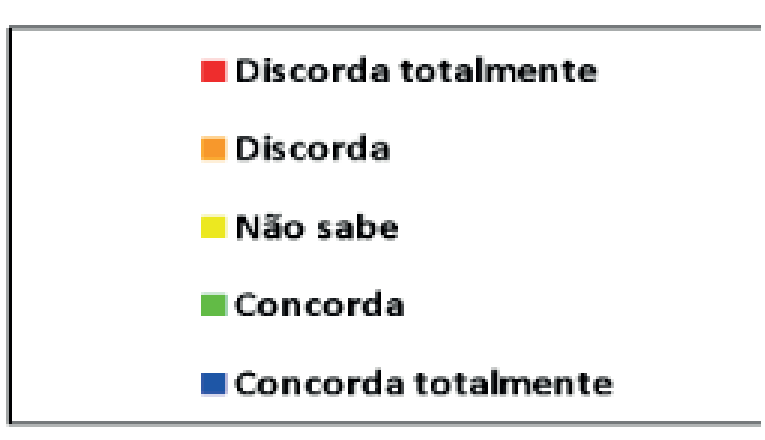

Observa-se que não há grande diferença aqui: precisamos mentir para fins de educação (polidez, cortesia).

29 有时候为了避免不礼貌和不温柔的言行，我们需要撒谎。In: CABRAL， Pedro Regis. 中国巴西 文化差异对汉语二语教学的影响一一以谦虚文化、等级关系和性别文化为例 (A influência de diferenças culturais entre Brasil e China no ensino de chinês como segunda língua: o caso da cultura da modéstia, relações hierárquicas e relações entre os sexos). Tese (mestrado em ensino de chinês como segunda língua) Faculdade de Língua e Cultura Chinesa, Universidade de Estudo Estrangeiros de Cantão, Cantão, 2017, p.24. 
Gráfico 2: A etiqueta social (polidez, cortesia, educação) não tem necessariamente relação com a moral. ${ }^{30}$

Brasileiros

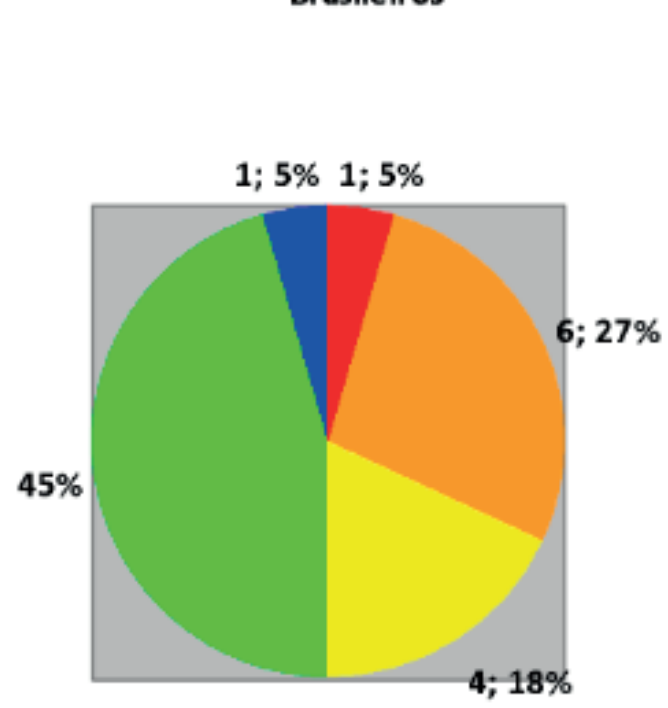

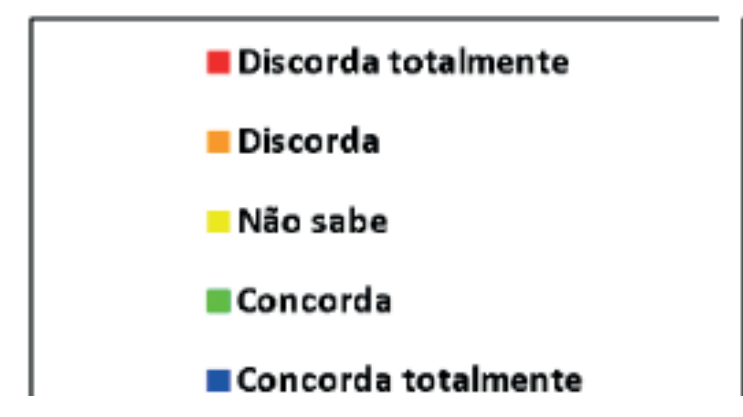

Chineses

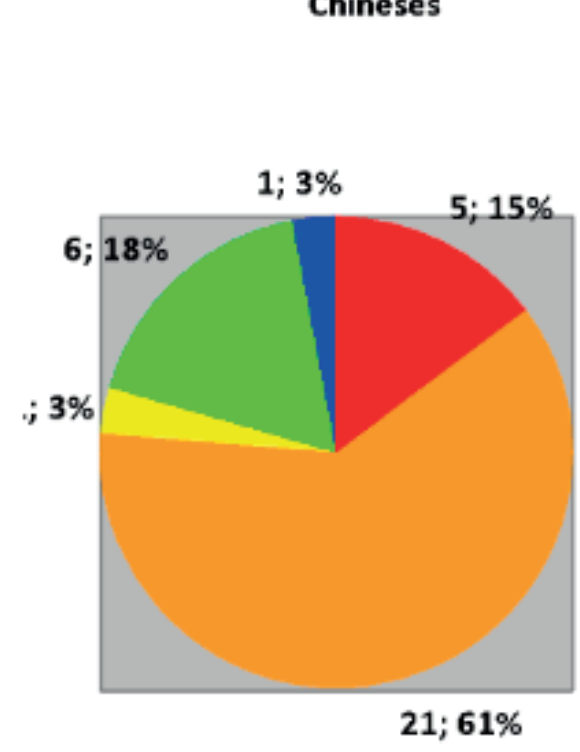

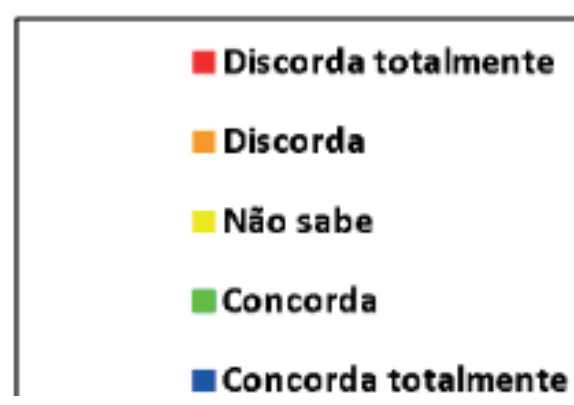

Aqui podemos observar com clareza que chineses tendem mais que brasileiros a ver a educação (polidez, cortesia) como um requisito moral.

\begin{tabular}{l}
\hline 30 礼貌跟道德没有必然的关系。CABRAL, Pedro Regis. 中国巴西文化差异对汉语二语教学的影响 \\
一以谦虚文化、等级关系和性别文化为例 (A influência de diferenças culturais entre Brasil e \\
China no ensino de chinês como segunda língua: o caso da cultura da modéstia, relações hierárquicas \\
e relações entre os sexos). Tese (mestrado em ensino de chinês como segunda língua) - Faculdade \\
de Língua e Cultura Chinesa, Universidade de Estudo Estrangeiros de Cantão, Cantão, 2017, p. 25. \\
50
\end{tabular}


Gráfico 3: Agir insinceramente é faltar com a educação (polidez, cortesia). ${ }^{31}$

Brasileiros
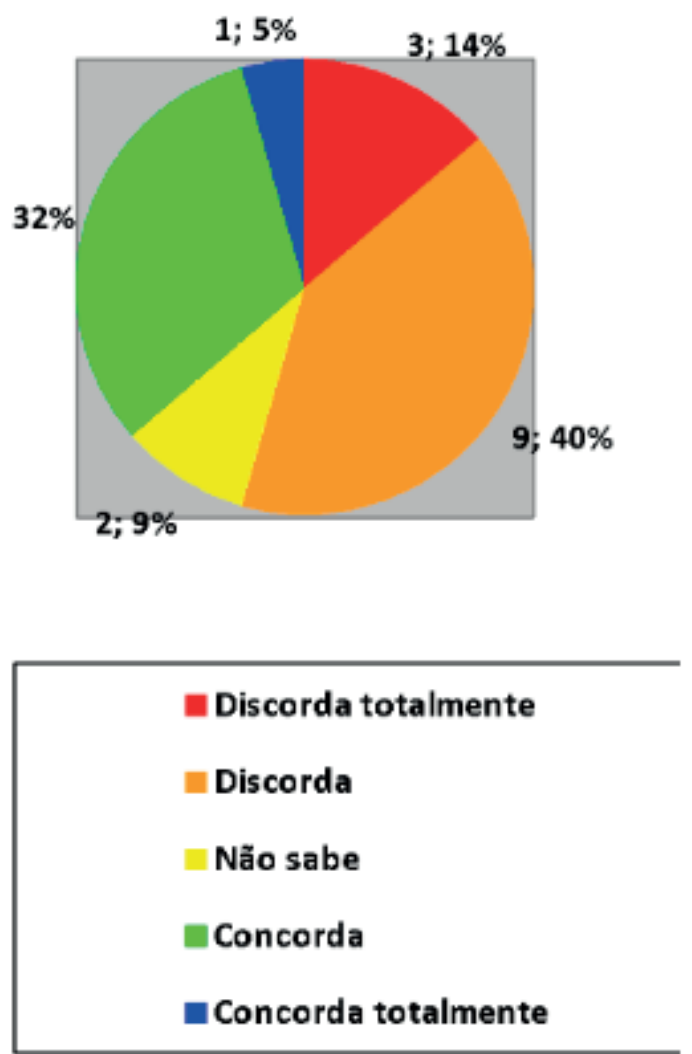

Chineses

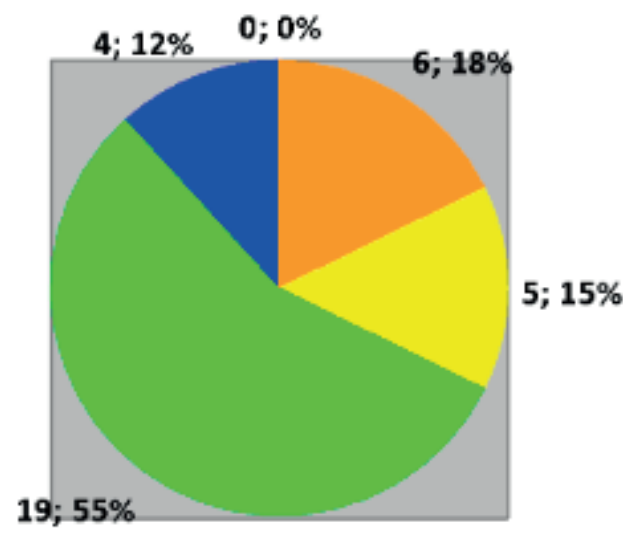

Os chineses insistem: não há educação (polidez, cortesia) sem sinceridade (gráfico 3). Se a educação (polidez, cortesia) implica em moral (gráfico 2), conclui-se que ser sincero é ser moral e que, paradoxalmente, mentiras ditas no intuito de evitar descortesias (gráfico 1) não são, no fim, “insinceras”, mas antes uma tentativa sincera de não ferir o orgulho de outra pessoa em um contexto em que respostas totalmente factuais não são necessariamente esperadas. "Mentiras brancas" são “mentiras sinceras". Talvez morais.

31 不真诚的言行很不礼貌。In: CABRAL， Pedro Regis. 中国巴西文化差异对汉语二语教学的影响 以谦虚文化、等级关系和性别文化为例 (A influência de diferenças culturais entre Brasil e China no ensino de chinês como segunda língua: o caso da cultura da modéstia, relações hierárquicas e relações entre os sexos). Tese (mestrado em ensino de chinês como segunda língua) - Faculdade de Língua e Cultura Chinesa, Universidade de Estudo Estrangeiros de Cantão, Cantão, 2017, p. 26. 
Zi Yue: revista de graduação de estudos sinológicos. São Paulo: Portal de Revistas da USP, v. 1, n. 1, 2020.

O termo moderno chinês para educação (no sentido de polidez, cortesia) é constituído por dois caracteres: “禮貌” (lǐmào), o primeiro sendo precisamente “禮”, ou “rito”, o conceito do qual estamos tratando aqui. O termo moderno para polidez não é idêntico ao conceito antigo de rito, como apontamos em nossa tese de mestrado, mas tem sua origem nele ${ }^{32}$ e há certa correspondência entre ambos, uma vez que se referem às formas, gestos, atitudes e palavras esperadas nas relações interpessoais. Observa-se que, para o espanto do ocidental, tanto a polidez como o rito estão intimamente associados a uma atitude sincera e não apenas às tais formas exteriores convencionalmente esperadas em relações interpessoais. Aqui, ressaltamos, não basta afirmar, como certos protestantes o poderiam fazer, que os chineses estão errados uma vez que os rituais podem ser feitos de forma insincera. O conceito chinês de rito não é somente descritivo: é também um ideal. Ele deve ser compreendido em seu próprio contexto ${ }^{33}$. Ho Yeh Chia disserta sobre o caráter ético do rito $^{34}$ e esclarece que desde a antiguidade havia clara diferença entre "rito" e “cerimônia”, esta enfatizando as formas exteriores, aquele enfatizando a expressão de sentimentos reais. ${ }^{35}$

\section{Considerações finais}

1. O rito, segundo as tradições bíblicas, está associado à relação do crente, ou da comunidade de crentes, com Deus. No caso hebreu, estava associado, conforme a tradição sacerdotal, à eficácia mágica e perdão de pecados, e os profetas criticando seu uso desprovido de sinceridade e ética. No caso dos cristãos, está associado à salvação da alma e perdão de pecados, protestantes do tipo não-conformista o criticando como um desvio da sã doutrina.

2. Em adição à natureza religiosa do rito, confucianos enfatizaram por séculos a sua função na organização social e fixação de papéis.

3. O rito pode ser usado para determinados fins políticos.

4. O rito representa e reflete a ordem cósmica na ordem social.

32 CABRAL, Pedro Regis. 中国巴西文化差异对汉语二语教学的影响一以以谦虚文化、等级关系和性别文化 为例 (A influência de diferenças culturais entre Brasil e China no ensino de chinês como segunda língua: o caso da cultura da modéstia, relações hierárquicas e relações entre os sexos). Tese (mestrado em ensino de chinês como segunda língua) - Faculdade de Língua e Cultura Chinesa, Universidade de Estudo Estrangeiros de Cantão, Cantão, 2017, p. 12. 33 Não queremos aqui fazer qualquer juízo de caráter moral (se é que isso é possível aqui). Mesmo no nosso contexto ocidental brasileiro não somos obrigados, por um dever de natureza moral, a falar sentenças factuais todo o tempo. Se perguntados por alguém com quem não temos grande familiaridade se estamos "bem", podemos perfeitamente "faltar com a sinceridade" e dizer que "sim". É perfeitamente aceitável e desejável para não se começar um diálogo inoportuno para ambas as partes. Em outras palavras, não há, está claro, nenhuma espectativa de afirmações factuais neste contexto. 34 HO, Yeh Chia. O Resgate do Coração Perdido: Virtude e Justiça na Educação Menciana. Tese (doutorado em educação) - Faculdade de Educação, Universidade de São Paulo, 2006, p. 174 35 緣人情而制禮，依人性而作儀。 
5. O rito, segundo a concepção confuciana, é moral. É um ideal a ser atingido.

6. Deve expressar o sentimento real de quem o pratica. "Patentear sinceridade e rejeitar tudo o que é hipocrisia, é a função do Cerimonial"36 (GUERRA, 1988, p. 305).

Mary Douglas traz reflexões que estão em concordância com uma concepção confuciana de rito ao ressaltar o seu caráter organizador da experiência. Os ritos são ordem.

\begin{abstract}
O estabelecimento de linhas e fronteiras simbólicas é uma forma de trazer ordem à experiência. Tais símbolos não-verbais são capazes de criar estruturas de significado nas quais indivíduos podem se relacionar uns com os outros e compreender seu propósito último. O aprendizado e a própria percepção dependem de classificação e distinção. Fronteiras simbólicas são necessárias até mesmo para a organização privada da experiência. Mas rituais públicos que performam essa função são também necessários para a organização da sociedade ${ }^{37}$ (DOUGLAS, 2007, p. 53).
\end{abstract}

Entendido dessa forma, não haveria razão para simplesmente condenar o ritual como vazio, insincero e mal em essência. Ainda Mary Douglas: "não é lógico desprezar todo ritual, toda ação simbólica por si mesmos. Usar a palavra ritual para significar símbolos vazios de conformidade é seriamente incapacitante para a sociologia da religião" ${ }^{38}$ (DOUGLAS, 2007, p. 3).

$\mathrm{O}$ católico Chesterton ridicularizava o quaker que se recusava à "cortesia" de tirar o chapéu a uma moça (superstition) $)^{39}$. Suspeitamos que Confúcio teria sido ainda mais enfático em condenar nosso antirritualismo.

\title{
Referências bibliográficas
}

\section{CABRAL，Pedro Regis. 中国巴西文化差异对汉语二语教学的影响一一以谦虚文化、}

等级关系和性别文化为例 (A influência de diferenças culturais entre Brasil e China no ensino de chinês como segunda língua: o caso da cultura da modéstia, relações hierárquicas e relações entre os sexos). Tese (mestrado em ensino de chinês como segunda língua) - Faculdade de Língua e Cultura Chinesa, Universidade de Estudo Estrangeiros de Cantão, Cantão, 2017.

Chesterton, G. K. All Things Considered. Disponível em: < http://www.personal. reading.ac.uk/ spsolley/GKC/Christmas\%28GKC\%29.html>. Acesso em: 26 dez.2017.

CONFÚCIO. Os Analectos. Tradução, comentários e notas Giorgio Sinedino. São Paulo:

\section{6 著誠去偽，禮之經也。}

37 Tradução nossa.

38 Tradução nossa.

39 No ensaio “Christmas" em All Things Considered. Em Disponível em: $<$ http://www.personal.reading.ac.uk/ spsolley/GKC/Christmas\%28GKC\%29.html>. Acesso em: 26/12/2017. 
Editora Unesp, 2012.

CONFÚCIO. Os Analectos. Tradução para o inglês e notas de Simon Leys; tradução Claudia Berliner. - $2^{\mathrm{a}}$ edição. - São Paulo: Martins Fontes, 2005.

DOUGLAS, Mary. Natural Symbols. London and New York: Routledge, 2007.

DOUGlas, Mary. Pureza e Perigo. Tradução Mônica Siqueira Leite de Barros, Zilda Zakia Pinto. - 2.ed. - São Paulo: Perspectiva, 2012.

GUERRA, JoaquimAngélico de Jesus. OCerimonial(Ley ky)2. Macau:Jesuítas Portugueses, 1988.

HO, Yeh Chia. O Resgate do Coração Perdido: Virtude e Justiça na Educação Menciana. Tese (doutorado em educação) - Faculdade de Educação, Universidade de São Paulo, 2006.

HU, Pingsheng (胡平生); CHEN, Meilan (陈美兰), 礼记孝经 (Livro dos ritos e Livro da piedade filial). Pequim: 中华书局 (Zhonghua Shuju), 2012, p. 171.

JIANG，Qing. 超越现代性与自由主义一一蒋庆先生与史罗一先生对话录 (Superando o Moderno e o Liberalismo - transcrição de diálogo entre Jiang Qing e Lioyd A. Sciban), Gui Yang, 2000. Disponível em:<http://www.confucius2000.com/scholar/jiangqingwenji.htm>.Acesso em:28jun.2014.

LI, Zehou (李泽厚). 中国古代思想史论 (Sobre a História do Pensamento Antigo Chinês). Pequim: 生活·读书·新知三联书店 (Shenghuo dushu xinzhi sanlianshudian), 2008. SELIGMAN, Adam B.; WELlER, Robert P.; PUETT, Michael J.; SIMON, Bennet. Ritual and Its Consequences. New York: Oxford University Press, 2008. WEBER, Max. A Ética Protestante e o "Espírito” do Capitalismo. Tradução de José Marcos Mariani de Macedo; revisão técnica, edição de texto, apresentação, glossário, correspondência vocabular e índice remissivo de Antônio Flávio Pierucci. - 14 a reimpressão. São Paulo: Companhia das Letras, 2004.

XUNZI. Hsün Tzu Basic Writings. Traduzido por Burton Watson. Nova Iorque e Londres: Columbia University Press, 1963.

XUNZI. 荀子集解•考证 (Coletânea e comentários sobre Xunzi: crítica textual). Taipé: 世界， 2000 .

ZENG ZI. Xiao Jing - The Classic of Xiao. English translation and commentary by Feng Xin-ming (May 2007, revised February and May 2008). Disponível em: <http://www.tsoidug.org/>. Acesso em: 09/10/2018. ZHOU, Zhenfu (周振甫). 周易译注 (Zhouyi yizhu). Pequim: 中华书局 (Zhonghua shuju), 2012. 